\title{
IMPLICAÇÕES DO CONCEITO DE CIDADANIA DE PROFESSORES SOBRE COMPORTAMENTOS PRÓ-ÉTICOS DE ESTUDANTES
}

\author{
Implications of teachers concept of citizenship on students pro-ethical behavior
}

\author{
Maria Flávia Frajácomo Ferreira ${ }^{[a]}$, Kester Carrara ${ }^{[b]}$ \\ ${ }^{[a]}$ Curso de Formação de Psicólogos (UNESP), Bolsista IC-FAPESP, Câmpus de Bauru, SP - Brasil: e-mail: \\ mflavia_ferreira@yahoo.com.br \\ ${ }^{[b]}$ Livre-docente, Professor titular da Universidade Estadual Paulista (UNESP), bolsista de Produtividade CNPq, Câmpus de \\ Bauru, SP - Brasil, e-mail: kestercarrara@pq.cnpq.br
}

\begin{abstract}
Resumo
Referir-se à cidadania apenas como aquisição de direitos é restringir o termo a uma compreensão simplista, já que esse conceito também implica práticas culturais complexas e aspectos políticos e filosóficos importantes da participação social. Na perspectiva da Análise do Comportamento, para que práticas culturais se modifiquem, buscando o bem da cultura e sua sobrevivência, comportamentos pró-éticos e pró-sociais precisam ser instalados e mantidos. A escola, além de priorizar a difusão do conhecimento, também é responsável por promover mudanças éticas socialmente relevantes, favorecendo o desenvolvimento integral do indivíduo e da comunidade. Nesse sentido, a educação cidadã se faz presente como forma de resgatar a cidadania, via participação social e, de uma forma mais abrangente, defender o "bem da cultura". Levando em consideração o fato de que comportamentos pró-éticos e pró-sociais são, em última instância, comportamentos socialmente habilidosos, esta pesquisa buscou identificar, em contexto escolar, qual o conceito de cidadania para docentes do ensino fundamental que passaram por um processo de capacitação em habilidades sociais em comparação com professores que não passaram por tal processo. Os resultados, nos quais aparece significativa valorização da participação para o grupo que passou pela capacitação, descrevem diferenças no conceito de cidadania para os dois grupos de professores.
\end{abstract}

Palavras-chave: Cidadania. Comportamentos pró-sociais. Análise do comportamento. 


\begin{abstract}
Referring to citizenship only as rights acquisition is to restrict the term to a simplistic understanding, since this concept also implies complex cultural practices and important political and philosophical aspects of social participation. In the perspective of Behavior Analysis, to cultural practices change, searching for the wellness of culture and its survival, behaviors proethical and prosocial need to be installed and maintained.

School, in addition to prioritize the dissemination of knowledge, is also responsible for promoting ethical changes socially relevant, promoting the whole development of the individual and the community. In this line of thought, civic education is present as a way to rescue the citizenship, by social participation and, in a larger form, to defend the "culture good". Taking into account the fact that pro-ethical and prosocial behaviors are, ultimately, socially skilled behaviors, this research sought to identify, in the school context, the concept of citizenship to elementary school teachers that went to a empowerment process in social skills comparing to teachers who not went through such process. The results, in which it appears significant valorization of the participation for the group that went through training, describe differences in the concept of citizenship for the two groups of teachers.
\end{abstract}

Keywords: Citizenship. Prosocial behavior. Behavior analysis.

\section{INTRODUÇÃO}

Equiparar cidadania à aquisição de direitos restringe o termo a uma caracterização reducionista: é consenso que o conceito de cidadania é abrangente, já que apenas a ideia de ter direitos pode significar, segundo Machado (1997), uma limitação na formação da pessoa com referência restrita ao cumprimento das deliberações advindas da Declaração Universal dos Direitos Humanos (DUDH) ou de outros documentos internacionais e nacionais com finalidade adjacente. O termo cidadania deve, então, abranger outros aspectos políticos e filosóficos relevantes para e no contexto de uma sociedade complexa.

Analisar tais aspectos caracterizadores de uma sociedade implica avaliar a participação dos indivíduos na sua organização e funcionamento. Tal participação depende de repertório pró-ético e prósocial.Oemprego das denominações "comportamentos pró-éticos" e "comportamentos pró-sociais" remete, diretamente, à noção de comportamentos socialmente habilidosos compatíveis com ainstalação e consolidação complexa da cidadania em diversos momentos do processo de desenvolvimento humano. Mais especificamente, embora também sejam comportamentos - na mesma dimensão que todos os demais envolvidos nos repertórios sociais típicos da cidadania - funcionam como uma espécie de prérequisitos para a consolidação desta.
O conceito de cidadania se modifica com a dinâmica da própria sociedade, com referência específica a transformações de ordem política, econômica, social e cultural. Assim, dizer o que é "adequado" para uma sociedade vai depender do aparecimento e desenvolvimento de práticas que a caracterizam e do momento histórico vigente por ocasião da sua análise histórico-científica. Portanto, o conceito de cidadania se modifica com as próprias transformações da sociedade, ao mesmo tempo produzindo-as e por elas sendo afetado. Segundo Skinner (1977), numa perspectiva ética, tais práticas de transformação devem estar voltadas para o próprio bem do indivíduo, para o bem do outro e, de forma mais abrangente, para o bem da cultura. De todo modo, no campo filosófico, parece infrutífera a busca de uma justificação racional para valores, de modo geral (Dittrich, 2008). Nossas escolhas de valores a serem adotados se pauta pela nossa experiência individual e/ou pelas práticas culturais de um determinado grupo social, não parecendo ser possível a adoção de valores ético-morais para além de alguma forma de experiência (pessoal ou grupo-cultural).

Skinner (1974/2003, p. 173) entende a cultura "como um conjunto de costumes ou maneiras, como um sistema de valores e idéias, como uma rede de comunicação, e assim por diante". Para o autor, o mais importante é entender que uma cultura evolui através de práticas que afetam a probabilidade do 
grupo vir a solucionar seus problemas. Assim, uma prática cultural é selecionada "devido à sua contribuição para a eficácia daqueles que a praticam" (Skinner, 1974/2003, p. 174). Além disso, o ambiente cultural seleciona certos comportamentos éticos dos indivíduos a fim de que estes ajam em benefício da sobrevivência da própria cultura. Quando se pensa em planejamento cultural, deve-se pensar na introdução de práticas culturais em função de suas consequências (Skinner, 1953/2000, p. 400). Ainda com Skinner (1953/2000), "faz-se uma mudança na prática porque mudanças semelhantes tiveram certas conseqüências no passado".

No caso de práticas incoerentes ou conflitantes entre si, Skinner (1974/2003, p. 174) sugere resultarem uma cultura e uma sociedade enfermas, em que "o homem carecerá de senso de identidade e de sentimentos de competência; assistirá à falência de suas próprias estruturas mentais...". Assim, Skinner entende que a sociedade só será "curada" quando as pessoas forem generosas e coerentemente reforçadas.

Para Skinner (1974/2003, p. 176), o que é bom para a espécie é aquilo que lhe ajuda a sobrevivência. O que é bom para o indivíduo é aquilo que lhe promove o bem estar. O que é bom para a cultura é aquilo que lhe permite solucionar os seus problemas.

Assim, agir em prol da sobrevivência da espécie e do bem-estar do indivíduo, buscando solucionar problemas, significaria agir eticamente. Skinner (1953/2000, p. 308) coloca que "geralmente se denomina o comportamento de um indivíduo como bom ou certo na medida em que reforça outros membros do grupo, e man ou errado na medida em que é aversivo". No entanto, o autor ainda coloca que um comportamento pode continuar sendo rotulado de "bom" ou "mau" mesmo com modificações na probabilidade de sua emissão futura (pode não ser mais reforçador ou aversivo). Nesse sentido, todos os comportamentos devem ser analisados de acordo com um contexto e não previamente rotulados.

Vale ressaltar que o comportamento de um indivíduo deve estar voltado para o bem do grupo; no entanto, não se deve perder de vista a necessidade de ações voltadas para o bem do próprio indivíduo. Assim, não se está defendendo um comportamento egoísta nem altruísta, mas um comportamento cidadão, que atenda a condições individuais, mas respeitando os direitos do grupo social onde se insere.
A partir dessas questões, entende-se que o desenvolvimento do comportamento cidadão, assim como o comportamento ético ou moral, é comportamento selecionado por contingências e que deve estar de acordo com o bem pessoal, do outro e da cultura.

De acordo com Carrara (1996), no caso brasileiro, frequentemente permeado por estratificação socioeconômica e política autoritária e hierarquizada, a elite "dispensa" os direitos do homem e do cidadão, já que possui privilégios que estão acima desses direitos. Em contrapartida, por vezes a maioria da população espera do Estado condições básicas para o alcance de uma equivocada cidadania, fruto de concessões, mais que de conquista. É importante considerar que "é mesmo inseparável do conceito de cidadania a idéia de conquista e não de dádiva" (Carrara, 1996, p. 13).

Pensar em cidadania como algo que o indivíduo adquire ou não (como um objeto que se possui ou se passa a possuir, por exemplo), nada explica sobre o seu comportamento. Dessa forma, percebe-se a necessidade de explicar o que seria, em termos comportamentais, o "ser cidadão".

Para se realizar tal descrição, conceitos como os de habilidades sociais e participação social são cruciais. Vale ressaltar que, numa ciência do comportamento, tanto as habilidades sociais quanto a participação social se referem, em última instância, a um complexo conjunto de respostas ante determinadas situações de interação social, podendo, assim, ser explicadas em termos comportamentais. Ou seja, a referência é feita em termos de instalação e desenvolvimento de determinados repertórios comportamentais com os quais cada pessoa, no contexto de práticas culturais definidas, interage com o contexto ambiental em que vive. Nesse sentido, a natureza de tal repertório é eminentemente social, implica preponderantemente comportamento verbal (mas não apenas) e mantém um vínculo indissociável com escolhas ético-morais de determinada sociedade.

No contexto de uma cidadania complexa, que está além do exercício de direitos e deveres, implicando aspectos psicológicos relevantes para o esclarecimento desse conceito central, o processo de instalação e consolidação de "comportamentos cidadãos" passa por etapas cruciais de desenvolvimento e aprendizagem, desde os primeiros instantes da vida individual. Nessas etapas, os prérequisitos para uma existência que respeita a justiça social costumam ser designados, como já se 
mencionou anteriormente, como comportamentos pró-éticos e/ou pró-sociais, visto que estes ensejam a instalação e/ou fortalecimento de um repertório eticamente comprometido com a justiça social.

Para que os comportamentos pró-éticos e pró-sociais sejam instalados e mantidos, as pessoas devem contar com uma série de habilidades sociais (habilidades aprendidas). Assim, parece clara a importância de se considerar algumas habilidades relevantes para o exercício da cidadania, como, por exemplo, a assertividade e a empatia.

Conforme Falcone (2001), para que haja uma boa interação entre as pessoas, estas devem ser capazes de compreender os desejos e sentimentos de outros indivíduos e demonstrar essa compreensão empática de forma verbal ou não-verbal. Nessa perspectiva, diz-se que um indivíduo é habilidoso socialmente quando possui essas capacidades ou competências.

De acordo com Caballo (1996, p. 364),

A habilidade social deve ser considerada dentro de um determinado marco cultural, e os padrões de comunicação variam amplamente entre culturas e dentro de uma mesma cultura, dependendo de fatores tais como a idade, o sexo, a classe social e a educação. Além disso, o grau de efetividade de uma pessoa dependerá do que deseja conseguir na situação particular em que se encontre. O comportamento considerado apropriado em uma situação pode ser, obviamente, impróprio em outra.

Ainda com Caballo (1996), pode-se perceber que o comportamento considerado habilidoso é aquele que (através de expressão adequada de sentimentos, atitudes, desejos, opiniões ou direitos), aumenta a probabilidade de resolução de problemas imediatos e minimiza a probabilidade de problemas futuros.

A participação social, de acordo com Carrara (1996), é mais efetiva quando resulta de um processo coletivo e planejado. É um processo em que não podem ser considerados objetivos terminais, no sentido de definitivos. Há sempre novas possibilidades a cada etapa alcançada. A questão da coletividade é importante já que, apesar da participação individual ser relevante, não alcança a amplitude e a generalidade possíveis mediante ações coletivas. Por fim, deve ser planejada e utiliza recursos variados, já que a busca pela participação social implica a utilização de instrumentos teóricos e práticos de diversas áreas de conhecimento. Para tanto, são imprescindíveis critérios e orientação bem definidos para utilização de tais instrumentos.
A Psicologia, enquanto área do conhecimento que também trata de questões relevantes para a construção da cidadania, tem muito com que contribuir para a sua consecução, devendo sempre ser levados em conta os aspectos processuais, o sentido de coletividade e o planejamento da participação social. Como instrumento de transformação social, a Educação cidadã se propõe a promover a difusão do conhecimento e também promover mudanças éticas desejáveis, de maneira que venham a favorecer o desenvolvimento integral do homem e da sociedade.

Tendo como base um cenário em que muitas escolas públicas brasileiras mantêm um perfil autoritário de ensino no qual o aluno é visto apenas como um receptáculo dos ensinamentos do professor, ficando, assim, passivo diante da participação dentro da escola, pode-se perceber que essa passividade também pode vir a se estender para a participação na sociedade como um todo. Por isso, a importância do desenvolvimento de pesquisas e estudos que possibilitem algum tipo de modificação no sistema educacional vigente no que diz respeito ao tema transversal das prescrições ético-morais que amparam o desenvolvimento e a consolidação da cidadania no contexto educacional.

Nesse sentido, a escola é administrada sem conseguir desvencilhar-se de aspectos burocráticos que atendem ao sistema vigente. Skinner (1953/2000, p. 370) menciona que "a função governamental pode também ser ativamente apoiada pelo grupo ético e instituições religiosas e educacionais com suas técnicas apropriadas."

A consequência desse processo educacional é a manutenção da estrutura social vigente, já que com o distanciamento entre conteúdo e realidade, o aluno não tem a possibilidade de pensar e discutir sobre as questões sociais, econômicas e políticas de sua realidade, bem como criticar e assumir uma posição nessas questões. Com frequência nota-se uma alienação por parte desses alunos. As transformações não são compreendidas em sua concretude; elas ficam presas somente ao plano das ideias. Assim, a cidadania deve necessariamente ultrapassar os muros da escola, alcançando todo o contexto social.

A importância de uma escola cidadã faz com que a necessidade de profissionais capacitados faça parte desta. Porém, segundo Skinner (1972, p. 90), “o professor principiante não recebe preparação profissional. Geralmente começa ensinando como 
foi ensinado e, se melhora, é apenas graças à sua própria e desamparada experiência." Isso pressupõe que na maioria das vezes os professores também não receberam uma educação cidadã.

Em especial, a escola fundamental desempenha relevante papel no desenvolvimento da cidadania, já que os adultos demonstram interações sociais positivas decorrentes de experiências vividas na infância. Deve-se, no entanto, ter clareza de que a criança não é um mero "vir a ser" (Andrade, 1998). Cabe à Educação e à Psicologia o papel de modificar essa visão. A criança é potencializada como agente transformador da sociedade. Uma estratégia simples, porém de extrema relevância, consiste na diminuição de coerções no meio educacional. Se a criança pode participar, opinar e criticar as normas da escola, não fica marginalizada do processo educacional. A partir disso, ela constrói gradativamente a sua atuação cidadã.

Enquanto tentativa de compreender tais aspectos no contexto de uma escola municipal de Ensino Fundamental (EMEF) de uma cidade do interior do Estado de São Paulo, esta pesquisa, baseada na perspectiva da Análise do Comportamento, teve como objetivo analisar o conceito de cidadania e suas implicações no desenvolvimento de comportamentos pró-éticos de professores dessa EMEF, com reflexos potenciais no repertório de seus alunos.

A ideia de analisar o conceito de cidadania para professoras de uma EMEF surgiu durante a realização de um projeto mais abrangente intitulado "Ensino fundamental, aprendizagem e desenvolvimento: um aporte da Psicologia à construção da cidadania" (projeto de pesquisa concluído em 2006 com apoio da Fapesp, no contexto do Edital de Ensino Público - processo número 2004/14157-0), o qual teve como principal objetivo avaliar o efeito de práticas educacionais que favorecessem o desenvolvimento da cidadania em escolares do ensino fundamental, através da consolidação de repertórios de comportamentos próéticos diversos e, particularmente, os que incluíam respeito à diversidade (Carrara et al., 2004, p. 17). Nesse projeto, foi realizado um Processo de Capacitação de Habilidades Sociais (PCHS), com a participação de 10 professores. Primeiramente, foram realizadas duas filmagens em cada classe, com duração de 20 minutos, em que o foco da observação era a interação educador-criança. Após a etapa de filmagens, foram realizados 12 encontros semanais da equipe de pesquisa e os educadores, com duas horas de duração cada. Os temas tratados nesses encontros foram definidos a partir da literatura e das observações feitas através das filmagens. Entre os temas abordados, sob a mediação teórica e conceitual da Análise do Comportamento, estavam: conceito de regras; definição de comportamentos pró-éticos e pró-sociais, bem como dificuldades encontradas para a sua promoção; diversidade humana na educação; comunicação; expressão de sentimentos positivos; conhecimento de direitos humanos básicos; expressar e ouvir opiniões; expressar sentimentos negativos; fazer e recusar pedidos; lidar com críticas; admitir os próprios erros; pedir desculpas; estabelecer limites; e relacionamento com a comunidade escolar (pais, servidores, auxiliares administrativos).

A partir de referenciais teóricos consolidados na literatura com Abib (2001), Banaco (2001), Baum (1999), Dittrich (2003; 2004), Skinner (1972; 1977; 1953/2000; 1974/2003), buscou-se levantar aspectos importantes para ampliar a compreensão acerca do posicionamento do Behaviorismo Radical frente a questões sociais complexas, tais como a dinâmica das práticas culturais, por exemplo. A partir de referências como Carrara (1996), Ciampa (1984) e Machado (1997) cotejaram-se as noções e implicações conceituais de cidadania, incluindo outras abordagens teóricas da Psicologia. Em Libâneo (1984), Saviani (2003) e Ribeiro (2002) buscou-se contribuição para a compreensão das diversas facetas da educação e a importância desta para a construção da cidadania. A partir de estudos publicados por Bolsoni-Silva e Marturano (2002), Caballo (1996), Del Prette e Del Prette (1999; 2001) e Falconi (2001) buscou-se entendimento acerca das habilidades sociais, vinculadas à ótica behaviorista radical.

Nesse contexto, o presente estudo teve como objetivo verificar se haveria ou não diferença significativa acerca do conceito de cidadania para: 1) professores de uma EMEF do interior do estado de SP que passaram pelo Processo de Capacitação em Habilidades Sociais - PCHS (processo contido no Projeto de Pesquisa citado anteriormente) e 2) professores da mesma instituição que não passaram por este processo.

De modo abrangente, testar tais relações entre variáveis permitiria avaliar a efetividade, no médio prazo, dos procedimentos de capacitação utilizados na pesquisa anterior. Todavia, em caso positivo e como possível efeito coadjuvante de tal procedimento, poderia se tornar possível cogitar da 
possível generalização dos efeitos desse procedimento em relação ao contexto de professores da instituição. Encontrar efeitos de generalização permitiria avanços nos processos de capacitação, no sentido de que, mesmo quando estabelecidos de modo amostral, assegurariam efeitos similares para a comunidade em geral. Essa possibilidade, examinada sob a ótica das práticas culturais defendida por Skinner (1953), sinalizaria a possibilidade de ampliação de intervenções e instruiria tecnologicamente a viabilidade das mesmas na realidade escolar a partir dos conceitos de habilidades sociais (Del Prette, 2001; Bolsoni-Silva \& Marturano, 2002), delineamentos culturais (Skinner, 1953/2000) e de metacontingências (Glenn, 1986). Os resultados da pesquisa buscarão discutir tais possibilidades.

\section{MÉTODO}

\section{Participantes}

Foram selecionados para este estudo três professores que haviam participado do PCHS e quatro professores que não haviam passado pelo PCHS, escolhidos aleatoriamente a partir do conjunto de docentes de classes equivalentes da mesma instituição de ensino. Observa-se que se tratava de sete participantes da mesma instituição escolar e que mantinham contato social-acadêmico entre si.

\section{Local de coleta de dados}

Os dados foram coletados na própria EMEF, em horários combinados com os professores. Os horários eram previamente agendados para os intervalos entre as aulas dos professores ou após o término de suas atividades acadêmicas.

\section{Instrumentos de coleta de dados}

A partir do referencial da Análise do Comportamento, foram elaborados dois questionários para coleta de dados. O primeiro questionário teve como objetivo avaliar o conceito de cidadania de uma forma abrangente. Nesse sentido, continha questões dissertativas que envolviam o que é ser cidadão e quais comportamentos são importantes para o desenvolvimento da cidadania nas relações entre os alunos, entre os professores, e entre a escola e a familia dos alunos. O segundo questionário teve como objetivo avaliar o grau de importância que os professores atribuíam a alguns comportamentos previamente listados. Dentre esses comportamentos, podem-se citar alguns como "conhecer mais a respeito da forma de funcionamento do governolocal e federal"; " preocuparse com deveres tais como: pagar impostos, usar cinto de segurança, recusar drogas, não jogar lixo no chão [...]"; "criar regras que sejam justas para todos"; "ouvir e compreender o que os outros dizem e sentem."

\section{Procedimento de coleta de dados}

Os questionários foram entregues separadamente. Em primeiro lugar, os professores responderam o primeiro questionário e somente depois foi entregue o segundo questionário. Optouse por esta separação, já que o segundo questionário continha vários comportamentos que poderiam ser usados para responder o primeiro questionário. Os professores responderam os questionários individualmente na presença da pesquisadora.

\section{Tratamento de dados}

Para análise do primeiro questionário, foram feitas categorizações das verbalizações dos professores que passaram pelo PCHS e dos professores que não passaram por esse processo. Essas categorizações consistiram em agrupar as verbalizações dos professores de acordo com os seguintes temas-critério: direitos e deveres; participação social; e regras de convivência (respeito, cooperação e importância da comunicação). A partir dessa categorização, buscou-se na literatura uma discussão para análise comparativa entre as duas amostras. Para a análise do segundo questionário, foi utilizada a prova estatística de Mann-Whitney para amostras pequenas.

\section{RESULTADOS E DISCUSSÃO}

\section{Primeiro questionário}

A partir da análise dos dados, pode-se perceber que no questionário de perguntas abertas, 
os professores que passaram pelo PCHS tiveram respostas mais completas no que se refere à inclusão da importância da participação social no conceito de cidadania. Algumas verbalizações da categoria "participar socialmente" podem ser citadas, como "participação consciente e ética, voltada para o bem do grupo, do social"; "trabalhar para minimização dos problemas sociais". No entanto, é válido citar uma verbalização de um professor que não participou do PCHS, qual seja "ter direito de participar socialmente". Colocando a participação social enquanto direito, pressupõese que as agências de controle devam possibilitar caminhos para que tal participação seja possível. As respostas dos dois grupos, embora as do primeiro sejam mais completas, mostram a educação concebida como um dos caminhos mais promissores (quando se fala de uma educação cidadã) para o alcance desse direito, no sentido de que este seja conquistado, ao invés de concedido.

Ainda no primeiro questionário, quanto aos comportamentos necessários para o desenvolvimento da cidadania nas interações sociais de que participam os alunos, os professores e a escola e a família, podem-se citar algumas verbalizações dos professores que passaram pelo PCHS incluídas na categoria "regras de convivência": "regras de conduta como respeito, trabalho em equipe, participação"; "habilidades como saber lidar com críticas, admitir os próprios erros e pedir desculpas, cooperar, dialogar"; "comunicação entre a família e a escola". Algumas verbalizações inseridas nessa mesma categoria (dos professores que não passaram pelo PCHS) também podem ser citadas: "compreender que estão inseridos em um grupo"; "unir-se"; "comprometer-se"; "maior participação da família nas atividades da escola"; "seguir regras de convivência"; "respeitar"; "cumprimento de direitos e deveres"; "habilidades como respeitar opiniões, trabalhar em grupo e colaborar"; "boa comunicação entre família e escola". Vale ressaltar a importância desta última categoria. Entende-se que a família deva fazer parte da comunidade escolar, a fim de que esteja em contato com as decisões e problemas, e assim, para que ambas, família e comunidade escolar, reivindiquem juntas a melhoria da educação. Quando há uma separação entre escola e família, há uma culpabilização pelo fracasso escolar por uma ou por outra: a escola culpa os pais, julgando-os muitas vezes negligentes, enquanto a família responsabiliza quase que inteiramente a escola e professores por um ensino de baixa qualidade. Pensar em comportamentos cidadãos na relação família-escola significa a possibilidade de ambas discriminarem, juntas, as múltiplas variáveis que cercam os problemas educacionais, sabendo assim identificar de que agência ou agências de controle devem reivindicar seus direitos. No entanto, as condições de vida familiar podem impossibilitar uma participação ativa na escola. Em uma escola de periferia (caso da escola estudada), em que os pais muitas vezes deixam os filhos na escola para trabalhar, muitos não têm tempo e nem motivação para participar da vida escolar. Outros, não sabem nem como participar, para além do gesto de comparecer às reuniões (quando comparecem).

\section{Segundo questionário}

Para análise do segundo questionário (questionário com perguntas fechadas), os 28 comportamentos pré-dados para que os professores os classificassem quanto ao grau de importância no que se refere ao desenvolvimento da cidadania, foram agrupados em quatro categorias: Categoria 1 Habilidades de comunicação: envolvem a expressão de sentimentos, opiniões, desejos, de forma assertiva; a compreensão da mensagem que o outro passou; respeito a sentimentos, opiniões e desejos alheios; Categoria 2 - Defesa dos próprios direitos e reconhecimento de deveres (inclusive a participação social): sabe-se que a cidadania não se reduz ao cumprimento dos deveres e dos direitos; no entanto, quando se coloca a importância da participação social, entende-se que o conceito se torna mais amplo e mais completo. Assim, a habilidade de reconhecer a importância da participação social como um dever para o benefício da cultura é de suma importância para o desenvolvimento da cidadania; Categoria 3 Cooperação: Cooperar para a resolução de problemas imediatos e diminuição da probabilidade de ocorrência de problemas futuros. Além disso, implica em saber a importância de trabalhar em grupos e privilegiar a coletividade em detrimento do individualismo; Categoria 4 - Desempenho interpessoal: Conjunto de respostas que implicam um bom desempenho de atitudes para uma boa relação interpessoal, como, por exemplo, ser empático. Aqui, também, se incluem as atitudes tomadas pelo professor como um bom profissional de sua área. 
As categorias foram selecionadas de acordo com Bolsoni-Silva e Marturano (2002), representando os principais comportamentos socialmente habilidosos que, no caso, contribuem para a construção da cidadania.

Foram feitas análises comparativas para cada categoria e para o somatório de todas as categorias. Foi adotado um intervalo de confiança (IC) de $95 \%$, sendo o nível de significância (á $=0,05)$. A partir dos escores levantados pela soma dos graus de importância atribuídos para cada professor em cada categoria, obteve-se o valor de U. Com o valor de $U$, foi consultada a "Tabela de probabilidades associadas a valores tão pequenos quanto aos valores observados de U na prova de Mann-Whitney" (Siegel, 1975 , p. 302), obtendo-se assim o valor de $p$, de maneira que, como se pode aferir na Tabela 1 :

\section{Hipóteses:}

Ho $-\mathrm{p}>$ 0,05 : não existe diferença significativa entre as amostras

$\mathrm{H}_{1}-\mathrm{p}<0,05$ : existe diferença significativa entre as amostras

Tabela 1 - Demonstração dos valores obtidos na análise comparativa entre as amostras estudadas

\begin{tabular}{lccc}
\hline Categorias & Valor de $\boldsymbol{U}$ & Valor de $\boldsymbol{p}$ & Decisão \\
\hline Categoria 1 & 6 & 0,571 & $\mathrm{p}>0,05$-aceita-se Ho. \\
Categoria 2 & 6 & 0,571 & $\mathrm{p}>0,05$-aceita-seHo. \\
Categoria 3 & 6 & 0,571 & $\mathrm{p}>0,05$-aceita-seHo. \\
Categoria 4 & 6 & 0,571 & $\mathrm{p}>0,05$-aceita-seHo. \\
Somatório & 3 & 0,1 & $\mathrm{p}>0,05$-aceita-seHo. \\
de todas & & & \\
as categorias & & & \\
\hline
\end{tabular}

Em função destes dados obtidos a partir da aplicação do segundo questionário, levantou-se a hipótese de possível generalização dos conteúdos contidos no Processo de Capacitação em Habilidades Sociais para os professores que não passaram por esse processo. Para verificar essa hipótese, foram feitas entrevistas com uma representante de cada grupo de professores. Nessas entrevistas, ambos os grupos confirmaram a hipótese, alegando que houve reuniões entre todos os professores, a fim de compartilharem os conteúdos aprendidos. Estas reuniões eram marcadas mensalmente, para que os professores compartilhassem experiências que obtiveram a partir de cursos, congressos, especializações e projetos de pesquisa que participaram. Assim, os responsáveis por repassar o conhecimento indicavam textos, livros, artigos para os demais.

Após a finalização do projeto, foi feita uma devolutiva para a escola a fim de socializar os resultados da pesquisa, bem como propor sugestões e elogiar aspectos importantes conquistados pela escola.

\section{CONSIDERAÇÕES FINAIS}

$\mathrm{Na}$ tentativa de identificar características e esclarecer o conceito de cidadania para professores de uma EMEF de uma cidade do interior de São Paulo, buscou-se apreender até que ponto estes estão cientes da possibilidade de contribuir para mudar sua realidade e o quadro de problemas sociais que compõem o tecido social onde vivem.

Através dos dados obtidos no primeiro questionário, os professores que passaram pelo PCHS souberam explicitar a importância da participação social para o desenvolvimento da cidadania, enquanto que a maioria dos professores que não passaram por esse processo não identificou com igual clareza tal possibilidade, ainda que tenha verbalizado parte importante de conceitos relacionados, como, por exemplo, a importância dos professores trabalharem em conjunto e a importância do comprometimento destes em sua atuação profissional. Já em relação aos comportamentos necessários para o desenvolvimento da cidadania entre os alunos, entre os professores e entre a família e a escola (referentes à segunda parte do $1^{\circ}$ questionário), ambos os grupos trouxeram contribuições importantes: levantaram aspectos cruciais, como a ética, respeito, colaboração, respeito às regras, necessidade de comunicação entre os professores, e entre a família e a escola. Como já explicitado anteriormente, no segundo questionário, não houve diferença estatística significativa entre os dois grupos, levantando a hipótese de uma possível generalização dos conteúdos para os professores que não passaram pelo PCHS.

Assim, nota-se que o aspecto $\mathrm{da}$ comunicação, citado indiretamente pelos professores de ambos os grupos no primeiro questionário, mostrou-se presente no dia a dia dos docentes, já que, em entrevista com um representante de cada grupo, pôde-se comprovar que os conteúdos referentes ao PCHS foram transmitidos para os professores que não passaram pelo processo de 
capacitação. Dessa forma, os participantes da pesquisa que não passaram pelo PCHS já haviam entrado em contato com questões referentes à cidadania no contexto de sua convivência com os colegas durante sua atuação na instituição.

Percebe-se que os professores não participantes do PCHS, apesar de não explicitarem, no ato de responder aos questionários, mencionaram a importância da participação social no desenvolvimento da cidadania e demonstraram em sua atuação profissional que estão preocupados com esta questão. Buscar a troca de conhecimentos e experiências, se interessar por aprender novas habilidades que favoreçam o desenvolvimento de comportamentos pró-éticos e pró-sociais (tanto dos alunos quanto dos próprios docentes) e trabalhar em conjunto são formas de participar socialmente dentro de uma comunidade escolar já privilegiadas pela maioria dos docentes da instituição estudada.

Percebe-se que o projeto realizado em 2005, intitulado "Ensino fundamental, aprendizagem e desenvolvimento: um aporte da Psicologia à construção da cidadania" (Carrara et al., 2004) levou os professores participantes a repensarem sua atuação profissional, de forma a colocá-la em acordo com o desenvolvimento e a consolidação da cidadania, inclusive difundindo este conhecimento para a rede de professores da escola estudada. Este fato mostra que, apesar de todas as deficiências estruturais da escola estudada, há um processo relevante de comunicação entre os professores. Para além de um trabalho realizado com um grupo de professores específico, o PCHS trouxe relevantes contribuições para a unidade escolar como um todo. A difusão do conhecimento que os professores que passaram pelo PCHS fizeram para os demais professores pode ser considerada como uma forma de participação social, como uma forma de atuação cidadã, que ultrapassa o bem do indivíduo e que se estende para o bem de toda uma comunidade escolar. Esse fato, visto sob a ótica da análise de práticas culturais atualmente em desenvolvimento pela Análise do Comportamento, permite identificar a importância do fenômeno do entrelaçamento de contingências para a instalação, consolidação e manutenção de repertórios de interação social complexos em determinadas comunidades. No caso presente, os dados sugerem que o papel multiplicador que as intervenções que consolida práticas voltadas ao desenvolvimento da cidadania asseguram, permitem cogitar da viabilidade de subsídios derivados das estratégias dos delineamentos culturais, dos conceitos de entrelaçamento e contingências e de metacontingências (Carrara, 2008; Glenn, 1986; Skinner, 1953/2000) para subsidiar a elaboração, desenvolvimento, implantação e avaliação de políticas públicas pautadas nos temas transversais. Nesse sentido, tendo como finalidade geral a ampliação das discussões e, especialmente, da vivência de situações que corroboram a construção da cidadania compatível com as prescrições contidas no cenário legal da Constituição Brasileira (direitos e deveres do cidadão, por exemplo), parece evidente o papel geral da Psicologia e a contribuição específica possível a partir da Análise do Comportamento para o avanço da qualificação das práticas culturais na escola. Os perfis esperados para tal tema, já sobejamente conhecidos e divulgados através dos Parâmetros Curriculares Nacionais (PCNs) poderiam servir de base para o estabelecimento de programas de apoio às comunidades escolares quando estas se defrontam com tal desafio.

De outra parte, como limitação do estudo, frise-se a parcimônia com que devem ser considerados os relatos verbais (neste caso, veiculados através dos instrumentos respondidos pelos professores), com o consequente limite de não se poder viabilizar o contato direto, via observação sistemática, com o dia-a-dia dos participantes para compreender se o discurso corresponde com precisão à realidade vivida na escola. Assim, para estudos posteriores, deixa-se como sugestão investigar essa questão, mediante estratégia metodológica adicional de observação direta e sistemática em substituição ou adicionalmente à utilização de instrumentos de aferição a partir de manifestações verbais orais ou escritas (questionários e entrevistas). De todo modo, tendo em conta todo o contexto de avaliação dos dados disponíveis, pode-se, com segurança, vislumbrar como auspicioso o procedimento de capacitação de professores para lidar com as questões dos comportamentos próéticos, pró-sociais e focados na cidadania, seja pelos resultados diretos já identificados pelo procedimento do projeto integrado, antes mencionado, seja pelo efeito da generalização dos resultados, que sugere o desenvolvimento de alterações na cultura das práticas educacionais vigentes na comunidade acadêmica estudada. 


\section{REFERÊNCIAS}

Abib, J. A. D. (2001). Teoria moral de Skinner e desenvolvimento humano. Psicologia: Reflexão e Crítica, 14(1), 107-117.

Andrade, A. N. de. (1998). A criança na sociedade contemporânea: Do 'ainda não' ao cidadão em exercício. Psicologia, Reflexão e Crítica, 11(1), 161-174. Recuperado em 04 maio 2005, da SciELO (Sientific Eletronic Library On Line): www.scielo.br

Banaco, R. A. (2001). Podemos nos beneficiar das descobertas da Ciência do Comportamento? In R. A. Banaco (Org.). Sobre comportamento e cognição: Aspectos teóricos, metodológicos e de formação em análise do comportamento e terapia cognitivista. Santo André: ESETec Editores Associados.

Baum, W. M. (1999). Compreender o behaviorismo: Ciência, comportamento e cultura. Porto Alegre: Artmed.

Bolsoni-Silva, A. T., \& Marturano, E. M. (2002). Práticas educativas e problemas de comportamento: Uma análise à luz das habilidades sociais. $\mathbf{R e -}$ vista Estudos de Psicologia, 7(2), 227-235. Recuperado em 26 set. 2006, da SciELO (Sientific Eletronic Library On Line): www.scielo.br

Caballo, V. E. (1996). O Treinamento em habilidades sociais. In V. E. Caballo (Org.). Manual de técnicas de terapia e modificação do comportamento (pp. 361-398). São Paulo: Santos.

Carrara, K. (1996). A psicologia e a construção da cidadania. Psicologia: Ciência e Profissão, 16(1), 12-17.

Carrara, K. (2008). Entre a utopia e o cotidiano: Uma análise de estratégias viáveis nos delineamentos culturais. Revista Psicologia, 1(1), p. 42-54.

Carrara, K., Almeida-Verdu, A. C., Bolsoni-Silva, A. T., Calais, S. L., Leite, L. P., \& Melchiori, L. E. (2004). Ensino fundamental, aprendizagem e desenvolvimento: Um aporte da psicologia à construção da cidadania na escola. Bauru: FAPESP. (Projeto de pesquisa processo número 2004/14157-0).

Ciampa, A. C. (1984). Identidade. In S. Lane, \& W. Codo (Org.). Psicologia social: O homem em movimento. São Paulo: Brasiliense.
Del Prette, Z. A. P., \& Del Prette, A. (2001). Habilidades sociais: biologia evolucionária, sociedade e cultura. In H. J. Guilhardi, M. B. B. P. Madi, P. P. Queiroz \& M. C. Scoz (Org.). Sobre comportamento e cognição: Expondo a variabilidade. Santo André: ESETec.

Del Prette, Z. A. P., \& Del Prette, A. (1999). A psicologia das habilidades sociais: Terapia e educação. Petrópolis: Vozes.

Dittrich, A. (2003). Introdução à filosofia moral Skinneriana. In C. E. Costa, J. C. Luzia, \& H. N. Sant'anna (Org.). Primeiros passos em análise do comportamento e cognição (pp. 11-24). Santo André: ESETec.

Dittrich, A. (2004). A ética como elemento explicativo do comportamento no Behaviorismo Radical. In M. Z. S. Brandão, F. C. S. Conte, F. S. Brandão, Y. K. Ingberman, V. L. M. Silva, \& S. M. Oliani (Org.). Sobre comportamento e cognição (pp. 21-26). Santo André: ESETec.

Dittrich, A. (2008). O problema da "justificação racional de valores" na filosofia moral skinneriana. Revista Psicologia, 1(1), 21-26.

Falcone, E. (2001). Habilidades sociais e ajustamento: o desenvolvimento da empatia. In R. R. Kerbauy (Org.). Sobre comportamento e cognição: Conceitos, pesquisa e aplicação, a ênfase no ensinar, na emoção e no questionamento clínico (pp. 273-278). Santo André: ESETec.

Glenn, S. S. (1986). Metacontingencies in Walden Two. Behavior Analysis and Social Action, 5(1-2), 2-8.

Libâneo, J. C. (1984). Tendências pedagógicas na prática escolar. In Democratização da escola pública: A pedagogia crítico-social dos conteúdos. São Paulo: Brasiliense.

Machado, N. J. (1997). Cidadania e educação. São Paulo: Escrituras.

Ribeiro, M. (2002). Educação para a cidadania: questão colocada pelos movimentos sociais. Educação e Pesquisa, 28(2). Recuperado em 04 mar. 2007, da SciELO (Sientific Eletronic Library On Line): www.scielo.br

Saviani, D. (2003). Pedagogia histórico-crítica: Primeiras aproximações. Campinas: Autores Associados. 
Siegel, S. (1975). Estatística não paramétrica para as ciências do comportamento. Rio de Janeiro: McGraw-Hill.

Skinner, B. F. (2000). Ciência e comportamento humano. São Paulo: Martins Fontes. (Originalmente publicado em 1953).

Skinner, B. F. (1977). O mito da liberdade. Rio de Janeiro: Edições Bloch.

Skinner, B. F. (2003). Sobre o Behaviorismo. São Paulo: Cultrix. (Orginalmente publicado em 1974).

Skinner, B. F. (1972). Tecnologia do ensino. São Paulo: EPU.

Recebido: 19/11/2008

Received: 11/19/2008

Aprovado: 24/03/2009

Approved: 03/24/2009

Revisado: 17/09/2009

Reviewed: 09/17/2009 